\title{
Prognostic Significance of ( I 8) F-Fluorodeoxyglucose - Positron Emission Tomography After Treatment in Patients With Limited Stage Small Cell Lung Cancer
}

\author{
Adedayo A. Onitilo, MD, MSCR, FACP; Jessica M. Engel, MSN, FNP; \\ Jennifer M. Demos, BA; and Bickol Mukesh, PhD
}

\begin{abstract}
Objective: Small cell lung cancer (SCLC) represents I5\% to $25 \%$ of lung cancers. Despite favorable initial treatment response rates, recurrence is likely and long-term prognosis dismal.Accurate measurement of therapy response is critical to determine which patients might be spared additional treatment, and potential side effects. ${ }^{18} \mathrm{~F}$-fluorodeoxyglucose positron emission tomography (PET) may help distinguish necrotic or fibrous tissue from residual cancer, thus informing further treatment and prognosis.
\end{abstract}

Design/Setting/Participants and Methods: Retrospective chart review study of limited stage SCLC patients with PET scanning within 4 months post-chemotherapy at Marshfield Clinic, Marshfield, Wisconsin. Diagnosis of SCLC occurred from December I, 200 I through December 3I, 2007.

Results: Twenty-two patients ( $7 \%)$ had post-treatment PET: I I positive, I I negative. Median duration from last chemotherapy to PET was 36 days (range, 3 to 125 days). Median follow-up for all patients was 34.4 months (range, 6.8 to 65.9 months). Estimated median progression-free survival for all patients was 8.1 months ( $95 \%$ confidence intervals [CI], 4.3 to 11.9 months), 10.5 months for PET negative $(95 \% \mathrm{Cl}, 8 . \mathrm{I}$ to $>57.8$ months) and 4.3 months for PET positive patients $(95 \% \mathrm{Cl}, 2.8$ to $>7.2$ months) $(P<0.007$, log-rank test). Median survival for all patients was 19.2 months $(95 \% \mathrm{Cl}, 10.3$ to $>65.8$ months). Estimated median survival for PET negative patients was longer than PET positive (29.2 versus 10.3 months, $P=0.10$ ).

Conclusion: Post-treatment PET, prognostically significant, may be underutilized.

Keywords: ${ }^{18 F-F D G-P E T ; ~ L i m i t e d ~ s t a g e ~ s m a l l ~ c e l l ~ l u n g ~ c a n c e r ; ~ P r o g n o s i s ; ~ R e c u r r e n c e ; ~ T r e a t m e n t ~}$

Reprint Requests: Adedayo A. Onitilo, MD, MSCR, FACP, Marshfield Clinic - Weston Center, 350I Cranberry Boulevard, Weston, WI 54476, Tel: 7|5-393-1400, Fax: 7|5-393-1399, Email: onitilo.adedayo@marshfieldclinic.org
Received: April 21, 2008

Revised: July 16, 2008

Accepted: July 30, 2008 doi: $10.3121 / \mathrm{cmr} .2008 .797$

do: $10.3121 / \mathrm{cmr} .2008 .797$ 
L ung cancer is one of the most common types of cancer in both men and women. In 2008, the American Cancer Society estimates 208,657 new cases of lung cancer will be diagnosed and 161,775 will die of the disease. ${ }^{1,2}$ Small cell lung cancer (SCLC) represents $15 \%$ to $25 \%$ of all lung cancers and occurs almost exclusively in smokers. At presentation $30 \%$ to $40 \%$ of patients with SCLC have limited stage disease, i.e. disease confined within the hemithorax or within one field of radiation. ${ }^{1-3}$

Overall response rates of up to $85 \%$ can be achieved in newly diagnosed patients with limited stage SCLC treated with a multiple drug regimen and concurrent radiation therapy, with a complete response in $40 \%$ to $60 \%$. $^{2,4,5}$ Median survival for limited stage SCLC is approximately 15 to 20 months with a 5 -year survival rate of $10 \%$ to $13 \%{ }^{4,6,7}$ Unfortunately, the majority of patients develop recurrent cancer. Long-term survival is uncommon in limited stage disease and rare in extensive stage disease. Thus, most patients with SCLC eventually require additional treatment for progressive disease.

Differentiation between necrotic or fibrous tissue and residual disease is a challenge of post-definitive therapy imaging. Computed tomography (CT) scans provide anatomical imaging and thus measurement of response that can have prognostic value, but may not be able to identify residual disease. Residual disease may remain that can only be detected by functional imaging such as ${ }^{18} \mathrm{~F}$-fluorodeoxyglucose (18F-FDG) positron emission tomography (PET). PET scanning has been proposed in other cancer types 8,9 (e.g., Hodgkin's lymphoma) as a supplemental assessment of disease status. Identification of residual disease that can only be detected by functional imaging may be important in lending salvage therapy opportunity to a specific subset of patients. ${ }^{10}$ Meta-analyses have shown that maintenance/consolidation chemotherapy improves survival in SCLC. ${ }^{11}$ In the Southwest Oncology Group (SWOG) 9713 study, $9 \%$ of patients with limited SCLC who achieved partial response during chemoradiation therapy achieved complete remission with consolidation. ${ }^{12}$ These observations suggest that with proper identification some patients may benefit from additional therapy, while sparing others with no viable cancer the excess toxicities of additional therapy. Functional imaging such as PET scanning may be helpful in this clinical situation, but the scientific validity needs to be borne out prospectively. We reviewed the prognostic significance of PET imaging in 22 patients with limited stage SCLC.

\section{Methods}

We retrospectively reviewed charts of all patients diagnosed with limited stage SCLC at Marshfield Clinic, a multi-specialty, multi-center system in Wisconsin between January 1, 1992 and December 31, 2007, after obtaining institutional review board permission to conduct the study. This study time period coincides with the availability of electronic medical record data at Marshfield Clinic. Although 16 years of data were evaluated, all patients who met eligibility criteria and were included in this study were diagnosed and treated between December 1, 2001 and December 31, 2007. Patients were included in the study if they had a histologic diagnosis of limited stage SCLC as determined by imaging studies and had post-treatment PET scanning within 4 months of the end of definitive chemotherapy treatment.

\section{Scanning}

PET scan technology has been available at our institution since December 1996 beginning with camera-based PET or coincidence imaging. Beginning August 9, 2001, dedicated mobile PET (Siemens ECAT) was provided and changed on August 8, 2004 to a mobile PET/CT (Siemens Biograph PET/CT). Mobile service ended December 28, 2005 at which time the current in-house dedicated PET/CT (Phillips Gemini GXL PET/CT) became available. Whole body PET/CT scans were performed following the standard protocol in the Division of Nuclear Medicine at our centers. The patients were asked to fast for at least 4 hours prior to the test, and to avoid alcohol, caffeine, and strenuous activity for 24 hours prior to the examination. Patients were given saline with intravenous placement. The random blood glucose level at the time of injection was measured and documented. A glucose level below $200 \mathrm{mg} / \mathrm{dL}$ was required before scanning. A quality control check was performed on patients suspected of exhibiting abnormal standard uptake values (SUV) before evaluating the scan by checking the max SUV of the liver (normal 26), bladder (normal 15-120), and brain (normal 3-16). An intravenous line was started with patients kept in a dimly lit, quiet room for 15 minutes prior to ${ }^{18} \mathrm{~F}-\mathrm{FDG}$ administration and 60 minutes after the injection at which time imaging was begun.

The patients were scanned with their arms above their head on the scanner in the craniocaudal direction in quiet respiration. For PET/CT, initially a non-diagnostic, non-contrast CT scan was performed for attenuation correction and anatomic localization followed by the PET scan. CT scan base-attenuation corrected and non-attenuation corrected PET images were obtained from the top of the head to the feet. The images were reconstructed in transverse, sagittal, and coronal planes in attenuation-corrected data sets. The images were viewed on the screen in $2 \mathrm{D}$ with localization capability and 3D-volume rendering with $\mathrm{CT}$ fusion. Image fusion was automatically performed by hardware acquisition and software reconstruction. Screen image captures of the areas of interest were taken in PET and CT windows to document the location on the rotational image in all three planes and the maximum SUV value.

\section{Scan Interpretation}

For this study, PET scan reports were reviewed as read by the nuclear medicine radiologist. Focal intense uptake, either by visual analysis or by maximum SUV $>2.5$, was considered a 
positive study. In the case of multiple sites of activity, the greatest SUV was used. No uptake or ill-defined diffuse areas of low-grade uptake were thought to represent nonmalignant lesions and were considered negative scans. SUVs were generated for all lesions using the region of interest analysis. SUV was calculated as the maximum dose detected in the lesion divided by the injected dose corrected for body weight $(\mu \mathrm{Ci} / \mathrm{g})$. Although an SUV $<2.5$ was considered negative, one patient had post-treatment PET that was determined to be negative by the radiologist and treating oncologist, despite an SUV of 4.7. Conversely, one patient, despite an SUV of 2.25, was determined to have a positive scan.

\section{Statistical Analysis}

Descriptive statistics were presented for baseline characteristics. The Kaplan-Meier product limit method was used to estimate overall and progression-free survivals. Log-rank test was used to compare survival curves between PET positive and negative groups. Overall survival was measured from the date of diagnosis to the date of death from any cause. The date of first progression was determined by the first date an imaging study confirmed progression. Progression-free survival time was measured from the date of last chemotherapy treatment to the date of first progression or death from any cause without previous progression. Survival times were censored at the dates of last contact for patients who were lost to follow-up. A $P$-value of $<0.05$ was considered to be statistically significant. All statistical analyses were carried out using SAS 9.1 (SAS Institute, Cary, NC).

\section{Results}

A total of 22 patients were included in this study with a mean age of 65.3 years (SD 10.2; range, 44 to 84 years); 12 (54.6\%) patients were female. Of these 22 patients, $13(59.1 \%)$ were current smokers. PET was positive in $11(50.0 \%)$ patients and negative in $11(50.0 \%)$ patients. Thirteen $(59.1 \%)$ received cisplatin/etoposide and $7(31.8 \%)$ received carboplatin/ etoposide and the remaining $2(9.1 \%)$ patients received cisplatin/irinotecan as first definitive chemotherapy. Median duration of first chemotherapy was 81 days (range, 50 to 126 days). The majority of patients $(90.1 \%)$ received 4 or more cycles of chemotherapy. Median duration between last chemotherapy to PET scan was 36 days (range, 3 to 125 days). Radiation was given to $16(72.7 \%)$ patients with a median dose of 4555 cGy (range, 4000 to $5400 \mathrm{cGy}$ ). Patients with significant comorbidities did not receive radiation due to the higher risk of radiation-induced toxicity. Nine patients $(40.9 \%)$ had prophylactic cranial irradiation and one patient (4.6\%) had surgery. No significant differences in age, gender, or disease stage were observed between PET positive and negative group patients (table 1 ).

The median follow-up period for all patients was 34.4 months (range, 6.8 to 65.9 months). At the last follow-up, 12 patients

Table 1. Patient characteristics.

\begin{tabular}{|c|c|c|c|c|c|c|c|c|c|}
\hline Patient & Gender & $\begin{array}{c}\text { Age at } \\
\text { diagnosis (y) }\end{array}$ & Living & Staging PET & $\begin{array}{l}\text { SUV maximum } \\
\text { staging }\end{array}$ & $\begin{array}{l}\text { SUV maximum } \\
\text { post-therapy }\end{array}$ & Treatment & $\begin{array}{c}\text { Response by } \\
\text { PET }\end{array}$ & $\begin{array}{c}\text { Response by } \\
\text { CT }\end{array}$ \\
\hline 1 & M & 56 & Yes & No & NA & 0 & C & $\mathrm{N}$ & PR \\
\hline 2 & M & 75 & No & Yes & 6.9 & 0 & C & $N$ & PR \\
\hline 3 & $\mathrm{~F}$ & 63 & Yes & Yes & 2.57 & 1.11 & S,C & $\mathrm{N}$ & PR \\
\hline 4 & $\mathrm{~F}$ & 63 & Yes & Yes & 5.6 & 0 & $\mathrm{C}, \mathrm{R}$ & $N$ & SD \\
\hline 5 & M & 77 & Yes & Yes & 11.54 & 0 & $\mathrm{C}, \mathrm{R}$ & $N$ & CR \\
\hline 6 & M & 68 & No & No & NA & 0.6 & $\mathrm{C}, \mathrm{R}$ & $N$ & SD \\
\hline 7 & $\mathrm{~F}$ & 56 & No & No & NA & 2.34 & $\mathrm{C}, \mathrm{R}$ & $\mathrm{N}$ & PR \\
\hline 8 & $\mathrm{~F}$ & 75 & Yes & Yes & 13.7 & 4.7 & $C, R$ & $N$ & $\mathrm{CR}$ \\
\hline 9 & M & 84 & Yes & No & NA & 2.5 & $\mathrm{C}, \mathrm{R}$ & $\mathrm{N}$ & NCR \\
\hline 10 & M & 52 & No & No & NA & 0 & $\mathrm{C}, \mathrm{R}$ & $\mathrm{N}$ & PR \\
\hline 11 & M & 57 & No & No & NA & NA & $\mathrm{C}, \mathrm{R}$ & $\mathrm{N}$ & PR \\
\hline 12 & $\mathrm{~F}$ & 64 & No & No & NA & 3.28 & $\mathrm{C}, \mathrm{R}$ & $\mathrm{P}$ & SD \\
\hline 13 & $\mathrm{~F}$ & 65 & Yes & No & NA & 3.9 & $\mathrm{C}, \mathrm{R}$ & P & PR \\
\hline 14 & $\mathrm{~F}$ & 60 & No & No & NA & 10.87 & $\mathrm{C}, \mathrm{R}$ & P & PR \\
\hline 15 & M & 70 & No & Yes & 0 & 8.46 & $\mathrm{C}, \mathrm{R}$ & P & PR \\
\hline 16 & $\mathrm{~F}$ & 82 & No & No & NA & 2.25 & $\mathrm{C}, \mathrm{R}$ & P & PR \\
\hline 17 & $\mathrm{~F}$ & 65 & Yes & Yes & 14.3 & 4.7 & $\mathrm{C}, \mathrm{R}$ & P & PR \\
\hline 18 & M & 44 & No & Yes & 5.7 & 5 & C & P & PD \\
\hline 19 & $\mathrm{~F}$ & 67 & Yes & No & NA & 23.5 & $\mathrm{C}, \mathrm{R}$ & P & CR \\
\hline 20 & $\mathrm{~F}$ & 83 & Yes & No & NA & 3.9 & $\mathrm{C}, \mathrm{R}$ & P & SD \\
\hline 21 & $\mathrm{~F}$ & 65 & No & No & NA & NA & $C, R$ & $P$ & PR \\
\hline 22 & M & 67 & Yes & Yes & NA & NA & C & $\mathrm{P}$ & NCR \\
\hline
\end{tabular}

CR, complete response; NA, not available; PET, positron emission tomography; PR, partial response; PD, progressive disease; NCR, near complete response; SD, stable disease; SUV, standard uptake values; C, chemotherapy: R, radiotherapy; S, surgery; P, positive; N, negative. 


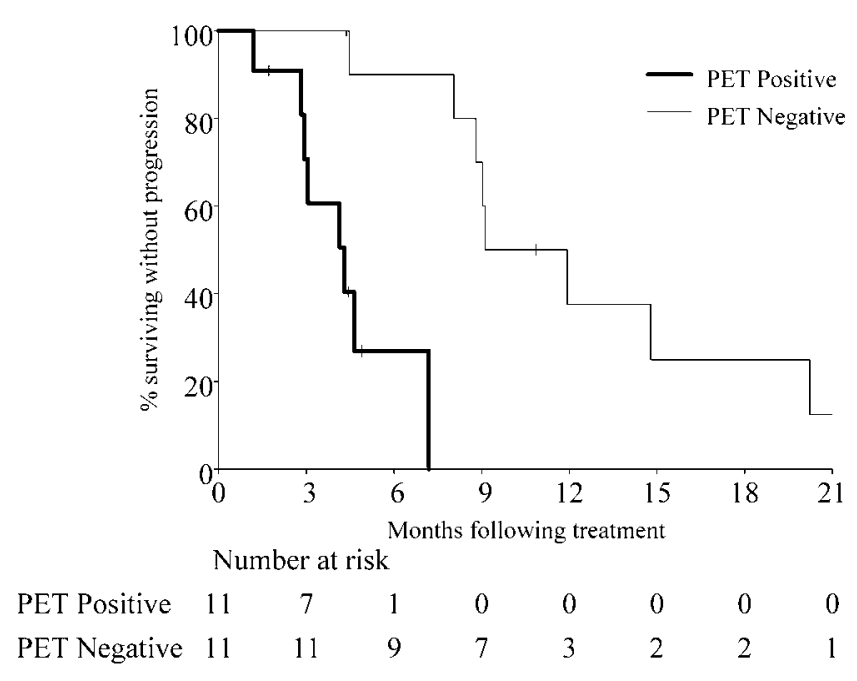

Figure 1. Progression-free survival $(P<0.007$, log-rank test).

(54.6\%) had died and $10(45.4 \%)$ were alive. Estimated median progression-free survival for all patients was 8.1 months (95\% CI range, 4.3 to 11.9 months). Progression-free survival for PET negative patients was 10.5 months $(95 \% \mathrm{CI}$, 8.1 to $>57.8$ months $)$ and 4.3 months $(95 \% \mathrm{CI}, 2.8$ to $>7.2$ months) for PET positive patients. This difference was statistically significant $(P<0.007$, log-rank test) (figure 1$)$. Median survival time for all patients was 19.2 months (95\% CI, 10.3 to $>65.8$ months). Although not statistically significant ( $P=0.10, \log$-rank test), estimated median survival time for PET negative patients (29.2 months; $95 \%$ CI, 12.4 to $>65.8$ months) was higher than for PET positive patients (10.3 months, 95\% CI, 7.2 to 39.4 months) (figure 2).

\section{Discussion}

Progression-free survival in our study for PET negative patients was longer (10.5 months) compared to PET positive patients (4.3 months), with an average time to progression for all patients of 8.1 months. Median survival time for all patients was 19.2 months, and although not statistically significant, the estimated median survival time for PET negative patients (29.2 months) was higher than the PET positive patients (10.3 months). PET imaging has been shown to be of value in initial staging, treatment, post-treatment, follow-up, and prognostic evaluation of other cancers. ${ }^{8-10,13}$ In SCLC, prior studies have shown the importance of PET imaging in initial staging and monitoring. ${ }^{14-18}$ These studies, however, included only a small number of patients and did not include post-therapy PET evaluation for prognostic purposes. Pandit et al ${ }^{19}$ evaluated prognostic information for post-treatment PET scanning in SCLC and determined that a positive post-treatment PET scan was a predictor of poor prognosis.

SCLC, a very aggressive form of lung cancer, is sensitive to both chemotherapy and radiation therapy. Despite a high percentage of initial response to therapy, there is a high recurrence rate. Accurate staging and early detection of residual and recurrent disease are important so that disease management can be suitably directed. CT scans are routinely used for staging and follow-up of these cases. However, CT scans are interpreted on the basis of size criteria and do not provide metabolic information. Dissolution and shrinkage of residual tumor mass is the final step in a complex cascade of cellular and subcellular changes post-therapy. This tumor dissolution and shrinkage may lag even after all viable tumor cells have been eradicated by therapy. It is not possible to biopsy every residual lesion post-therapy, thus, serial CT scans are an acceptable method for follow-up.

Response by CT was determined for each patient using the standard Response Evaluation Criteria In Solid Tumors (RECIST). The CT scan done in closest time proximity to the PET scan was used for comparison. Of the 11 patients with positive PET scan post-therapy, one patient had complete remission by $\mathrm{CT}$, one patient had a near complete response, eight had partial response or stable disease, and one patient had progressive disease. Of the 11 patients with a negative PET scan post-therapy, two patients had a complete response, one patient had a near complete response, and eight patients had partial response or stable disease. Based on the relapse-free interval and overall survival from this study, PET scan is more predictive of residual disease than CT scan.

We suggest that PET may be an underused method of imaging for the management and surveillance of patients with limited stage SCLC. In our study, from December 2001 through December 31, 2007, 326 patients were diagnosed with SCLC. The 22 patients in this paper therefore represent 7\% (22/326) of the total number of patients diagnosed with SCLC within the aforementioned 6-year period. A slowly increasing yet meager percentage of our patients with SCLC had post-treatment PET scans. The reluctance in obtaining

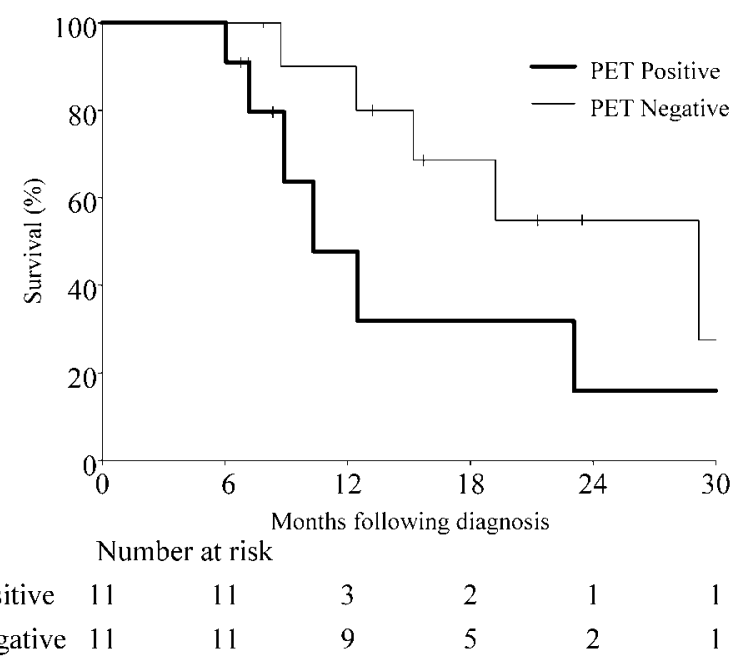

Figure 2. Overall survival ( $P=0.10$, log-rank test). 
post-therapy PET scans may be due to limited data support of the utility of testing, as well as economic reasons.

We appreciate the limitations of our study, including small sample size and other selection bias inherent to retrospective analysis. Due to patient comorbidities and treating physician and patient preference, definitive treatment was not identical for all patients. Staging PET scans were not available on every patient for comparison. Imaging reports as available in the patient medical record were used in this study, and scans were not re-read. Also, there was the introduction of the PET/CT scanner at our institution part-way through the study.

The findings from our study support a call for a prospective study of a larger sample size to evaluate the prognostic significance of post-therapy PET imaging. Furthermore, studies evaluating the role of consolidation/therapy in patients with responding disease whose post-therapy PET scan indicates residual disease should be proposed considering the current abysmal cure rate for SCLC.

\section{Conclusion}

We conclude that post-treatment 18F-FDG-PET/PET-CT scanning has prognostic significance and currently may be underutilized. We recommend a prospective study with a larger sample size to further evaluate the prognostic significance of post-therapy PET imaging.

\section{Acknowledgments}

The authors thank Marshfield Clinic Research Foundation for its support through the assistance of Linda Weis, Alice Stargardt, and Anne Nikolai in manuscript preparation.

\section{References}

1. American Cancer Society. Cancer Facts and Figures 2007. Atlanta, Ga: American Cancer Society, 2007. Available at: $\mathrm{http}: / /$ www.cancer.org/docroot/STT/stt_0_2007.asp?sitearea=STT\&level=1. Accessed July 11, 2008.

2. Chute CG, Greenberg ER, Baron J, Korson R, Baker J, Yates J. Presenting conditions of 1539 population-based lung cancer patients by cell type and stage in New Hampshire and Vermont. Cancer 1985;56:2107-2111.

3. Micke P, Faldum A, Metz T, Beeh KM, Bittinger F, Hengstler JG, Buhl R. Staging small cell lung cancer: Veterans Administration Lung Study Group versus International Association for the Study of Lung Cancer - what limits limited disease? Lung Cancer 2002:37:271-276.

4. Albain KS, Crowley JJ, Livingston RB. Long-term survival and toxicity in small cell lung cancer. Expanded Southwest Oncology Group experience. Chest 1991;99:1425-1432.

5. Johnson BE, Ihde DC, Bunn PA, Becker B, Walsh T, Weinstein ZR, Matthews MJ, Whang-Peng J, Makuch RW, Johnston-Early A. Patients with small-cell lung cancer treated with combination chemotherapy with or without irradiation. Data on potential cures, chronic toxicities, and late relapses after a five- to eleven-year follow-up. Ann Intern Med $1985 ; 103: 430-438$.
6. Lassen U, Osterlind K, Hansen M, Dombernowsky P, Bergman B, Hansen HH. Long-term survival in small-cell lung cancer: posttreatment characteristics in patients surviving 5 to $18+$ years - an analysis of 1,714 consecutive patients. J Clin Oncol 1995;13:1215-1220.

7. Spiegelman D, Maurer LH, Ware JH, Perry MC, Chahinian AP, Comis R, Eaton W, Zimmer B, Green M. Prognostic factors in small-cell carcinoma of the lung: an analysis of 1,521 patients. J Clin Oncol 1989;7:344-354.

8. Avril NA, Weber W. Monitoring cancer treatments using [18F] fluorodeoxyglucose positron emission tomography. In: Govindan R, ed. American Society of Clinical Oncology Educational Book: 43rd Annual Meeting. Alexandria, VA: American Society of Clinical Oncology; 2007: 15-19.

9. Rohren EM, Turkington TG, Coleman RE. Clinical applications of PET in oncology. Radiology 2004; 231:305-332.

10. Israel O, Kuten A. Early detection of cancer recurrence: 18 F-FDG PET/CT can make a difference in diagnosis and patient care. J Nucl Med 2007;48(suppl 1):28S-35S.

11. Bozcuk H, Artac M, Ozdogan M, Savas B. Does maintenance/consolidation chemotherapy have a role in the management of small cell lung cancer (SCLC)? A metaanalysis of the published controlled trials. Cancer 2005; 104:2650-2657.

12. Edelman MJ, Chansky K, Gaspar LE, Leigh B, Weiss GR, Taylor SA, Crowley J, Livingston R, Gandara DR. Phase II trial of cisplatin/etoposide and concurrent radiotherapy followed by paclitaxel/carboplatin consolidation for limited small-cell lung cancer: Southwest Oncology Group 9713. J Clin Oncol 2004;22:127-132.

13. Buatti J, Yao M, Dornfeld K, Skwarchuk M, Hoffman HT, Funk GF, Smith RB, Graham SM, Menda Y, Graham MM. Efficacy of IMRT in head and neck cancer as monitored by post-RT PET scans. Int J Radiat Biol Phys 2003;57(2 suppl):S305.

14. Chin R Jr, McCain TW, Miller AA, Dunagan DP, Acostamadiedo J, Douglas Case L, Harkness BA, Adler LP, Haponik EF. Whole body FDG-PET for the evaluation and staging of small cell lung cancer: a preliminary study. Lung Cancer 2002;37:1-6.

15. Fischer BM, Mortensen J, Langer SW, Loft A, Berthelsen AK, Daugaard G, Hansen HH. PET/CT imaging in response evaluation of patients with small cell lung cancer. Lung Cancer 2006;54:41-49.

16. Kut V, Spies W, Spies S, Gooding W, Argiris A. Staging and monitoring of small cell lung cancer using [18F]fluoro-2-deoxy-D-glucose-positron emission tomography (FDG-PET). Am J Clin Oncol 2007;30:45-50.

17. Schumacher T, Brink I, Mix M, Reinhardt M, Herget G, Digel W, Henke M, Moser E, Nitzsche E. FDG-PET imaging for the staging and follow-up of small cell lung cancer. Eur J Nucl Med 2001;28:483-488.

18. Zhao DS, Valdivia AY, Li Y, Blaufox MD. 18F-fluorodeoxyglucose positron emission tomography in small-cell lung cancer. Semin Nucl Med 2002; 32:272-275.

19. Pandit N, Gonen M, Krug L, Larson S. Prognostic value of $\left[{ }^{18} \mathrm{~F}\right]$ FDG-PET imaging in small cell lung cancer. Eur J Nucl Med 2003;30:78-84. 


\section{Author Affiliations}

Adedayo A. Onitilo, MD, MSCR, FACP

Department of Hematology/Oncology

Marshfield Clinic - Weston Center

3501 Cranberry Boulevard

Weston, Wisconsin 54476

Jessica M. Engel, MSN, FNP

Department of Hematology/Oncology

Marshfield Clinic

1000 North Oak Avenue

Marshfield, Wisconsin 54449

Jennifer M. Demos, BA

Department of Hematology/Oncology

Marshfield Clinic

1000 North Oak Avenue

Marshfield, Wisconsin 54449

Bickol Mukesh, PhD

Biomedical Informatics Research Center Marshfield Clinic Research Foundation 1000 North Oak Avenue

Marshfield, Wisconsin 54449 